\title{
Trends and variability of midlatitude stratospheric water vapour deduced from the re-evaluated Boulder balloon series and HALOE
}

\author{
M. Scherer ${ }^{1}$, H. Vömel ${ }^{2,3}$, S. Fueglistaler ${ }^{4}$, S. J. Oltmans ${ }^{3}$, and J. Staehelin ${ }^{1}$ \\ ${ }^{1}$ Atmospheric and Climate Science, Eidgenössische Technische Hochschule, Zürich, Switzerland \\ ${ }^{2}$ Cooperative Institute for Research in Environmental Science, University of Colorado, Boulder, CO, USA \\ ${ }^{3}$ Global Monitoring Division, Earth System Research Laboratory, NOAA, Boulder, CO, USA \\ ${ }^{4}$ Applied Mathematics and Theoretical Physics, Cambridge University, Cambridge, UK
}

Received: 13 August 2007 - Published in Atmos. Chem. Phys. Discuss.: 11 October 2007

Revised: 17 January 2008 - Accepted: 31 January 2008 - Published: 7 March 2008

\begin{abstract}
This paper presents an updated trend analysis of water vapour in the lower midlatitude stratosphere from the Boulder balloon-borne NOAA frostpoint hygrometer measurements and from the Halogen Occulation Experiment (HALOE). Two corrections for instrumental bias are applied to homogenise the frostpoint data series, and a quality assessment of all soundings after 1991 is presented. Linear trend estimates based on the corrected data for the period 1980-2000 are up to $40 \%$ lower than previously reported. Vertically resolved trends and variability are calculated with a multi regression analysis including the quasi-biennal oscillation and equivalent latitude as explanatory variables. In the range of 380 to $640 \mathrm{~K}$ potential temperature $(\approx 14$ to $25 \mathrm{~km}$ ), the frostpoint data from 1981 to 2006 show positive linear trends between $0.3 \pm 0.3$ and $0.7 \pm 0.1 \% / \mathrm{yr}$. The same dataset shows trends between $-0.2 \pm 0.3$ and $1.0 \pm 0.3 \% / \mathrm{yr}$ for the period 1992 to 2005 . HALOE data over the same time period suggest negative trends ranging from $-1.1 \pm 0.2$ to $-0.1 \pm 0.1 \% / y$. In the lower stratosphere, a rapid drop of water vapour is observed in 2000/2001 with little change since. At higher altitudes, the transition is more gradual, with slowly decreasing concentrations between 2001 and 2007. This pattern is consistent with a change induced by a drop of water concentrations at entry into the stratosphere. Previously noted differences in trends and variability between frostpoint and HALOE remain for the homogenised data. Due to uncertainties in reanalysis temperatures and stratospheric transport combined with uncertainties in observa-
\end{abstract}

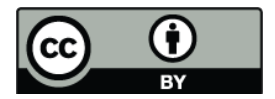

Correspondence to: S. Fueglistaler (s.fueglistaler@damtp.cam.ac.uk) tions, no quantitative inference about changes of water entering the stratosphere in the tropics could be made with the mid latitude measurements analysed here.

\section{Introduction}

Water vapour is important in determining radiative and chemical properties of the stratosphere (Kley et al., 2000). An increase of stratospheric water vapour of $1 \%$ per year has been reported for measurements made in Boulder, Colorado since 1980 (Oltmans and Hofmann, 1995; Oltmans et al., 2000) and, based on a combination of several datasets, for the past half century (Rosenlof et al., 2001). These trends indicate a long-term climate change (Rosenlof et al., 2001) and have implications for the Earth's radiative budget (Forster and Shine, 2002), stratospheric temperature and ozone chemistry (Dvortsov and Solomon, 2001). Uncertainties about future stratospheric $\mathrm{H}_{2} \mathrm{O}$ concentration affect the ability to predict the recovery of stratospheric ozone (Weatherhead and Andersen, 2006).

The reason for the observed increase is not clear at present. The photo oxidation of methane is the primary source of water vapour in the stratosphere, and the longterm increase in stratospheric $\mathrm{CH}_{4}$ can account for 24$34 \%$ of an increase of $1 \% / \mathrm{yr}$ in stratospheric $\mathrm{H}_{2} \mathrm{O}$ (Rohs et al., 2006). Interannual variability of the entry value of water vapour into the stratosphere $\left(\left[\mathrm{H}_{2} \mathrm{O}\right]_{\mathrm{e}}\right)$ is tightly constrained by tropical tropopause temperatures (Fueglistaler et al., 2005; Fueglistaler and Haynes, 2005). However, the water vapour trend observed by Oltmans et al. (2000) and Rosenlof et al. (2001) is at odds with temperature trends

Published by Copernicus Publications on behalf of the European Geosciences Union. 
at the tropical tropopause (Zhou et al., 2001; Seidel et al., 2001). The increase of El-Niño Southern Oscillation conditions over the last half century (Scaife et al., 2003), Volcanic eruptions (Joshi and Shine, 2003; Austin et al., 2007) or changes in cloud microphysical properties (Sherwood, 2002; Notholt et al., 2005) may have affected stratospheric water vapour, but clear evidence that any of these processes could account for the magnitude of the observed trend is missing.

Water vapour measurements at stratospheric concentrations (typically a few parts per million) are difficult and require sophisticated techniques. The NOAA Earth System Research Laboratory Global Monitoring Division (NOAA ESRL GMD) (formerly NOAA CDML) balloon-borne measurements with a frostpoint hygrometer (henceforth termed NOAA FP) is the only available continuous multi-decade record, covering the last 27 years. This series is one of the most often used dataset for stratospheric water vapour; either for comparisons with satellite data and models, or for studies investigating the effect of increasing stratospheric moisture (e.g. Forster and Shine, 2002; Sherwood, 2002; Shindell, 2001; Randel et al., 2001, 2004, 2006; Stenke and Grewe, 2005; Fueglistaler and Haynes, 2005; Chiou et al., 2006; Austin et al., 2007). However, assessment of trends is complicated by unresolved discrepancies between measurements of different instruments (see Kley et al., 2000). NOAA FP and Halogen Occultation Experiment (HALOE) (Russell et al., 1993) time series show systematic differences for trend estimates (Randel et al., 2004).

Here, we provide a new analysis of the NOAA FP data set and compare it with HALOE data for the period 1992-2005. Section 2 discusses data and bias corrections. The statistical model used to calculate trends and variability is described in Sect. 3, and Sect. 4 presents the results. Section 5 addresses the question whether the midlatitude water vapour measurements provide new insight into processes controlling $\left[\mathrm{H}_{2} \mathrm{O}\right]_{\mathrm{e}}$. Finally, Sect. 6 summarises our conclusions.

\section{Data}

\subsection{NOAA frostpoint hygrometer}

The NOAA FP is a balloon borne instrument based on the chilled-mirror principle. The Clausius-Clapeyron equation is used to determine the vapour pressure over an ice layer which is in equilibrium with the water vapour above. The instrument has been previously described (Oltmans, 1985; Vömel et al., 1995; Oltmans et al., 2000). The overall accuracy for this instrument is about $0.5 \mathrm{~K}$ in frostpoint temperature (Vömel et al., 1995), corresponding to about $10 \%$ in mixing ratio under stratospheric conditions. The balloon soundings typically reach an altitude of $28-30 \mathrm{~km}$. The design of the instrument allows collection of data during ascent and descent. Outgassing of water vapour in the NOAA FP inlet and from the balloon envelope is a source of possible contamination during ascent, but not during descent (when the instrument is ahead of the balloon). Generally, uncontaminated data can be collected up to an altitude of about $25 \mathrm{~km}$. All data before 1991 were manually extracted from a recorder strip chart. From 1991 onwards a digital recording system was implemented together with other new electronics. The dataset used in this study has been significantly revised compared to the dataset used by Oltmans et al. (2000). The next two sections document these changes.

\subsubsection{Data corrections}

Since the publications of Oltmans et al. (2000) and Rosenlof et al. (2001) two sources of bias in the measurement of the frostpoint temperature were identified. The first bias is due to the calibration of the thermistor, which measures the mirror temperature that is reported as frostpoint temperature. All thermistors are calibrated at three fixed temperatures $\left(0^{\circ} \mathrm{C}\right.$, $-45^{\circ} \mathrm{C}$ and $-79^{\circ} \mathrm{C}$ ). A model fit (Layton, 1961) based on the resistance at these three temperatures is used to describe the relationship between resistance and mirror-temperature. An extended calibration over the temperature range from $-100^{\circ} \mathrm{C}$ to $+20^{\circ} \mathrm{C}$ has shown differences between the modelled and the actual temperature (Vömel et al., 2007b). For temperatures below $-79^{\circ} \mathrm{C}$ the difference between model and real temperature becomes increasingly significant, with a warm bias reaching $0.16^{\circ} \mathrm{C}$ at a frostpoint temperature of $-90.0^{\circ} \mathrm{C}$. The Naval Research Laboratory (NRL) handbook included a linear correction $\left(T_{\mathrm{fp}, \text { corr }}=1.013245 T_{\mathrm{fp}}+1.0464\right)$ for frostpoint temperatures below $-79^{\circ} \mathrm{C}$, based on a few measurements at $-94.3^{\circ} \mathrm{C}$. Previously published data (erronously) applied this correction only up to 1991 . Here, we also correct the data from 1991 onward, using the following, improved correction for frostpoint temperatures below $-79^{\circ} \mathrm{C}\left(T_{\mathrm{fp}}\right.$ in $\left.{ }^{\circ} \mathrm{C}\right)$

$T_{\text {fp }, \text { corr }}=T_{\text {fp }}-\left(-0.029\left(T_{\mathrm{fp}}+79\right)+0.083\right)^{2}$

The difference between this improved and the old linear NRL correction is about a factor of 30 smaller than the total uncertainty of the measurement such that using two slightly different corrections for pre- and post-1991 data is not a problem.

A second issue is the self-heating of the thermistors in the calibration setup used prior to 1987 . The multi-meter current used to read the thermistor resistance at $0^{\circ} \mathrm{C}$ was too large and caused significant self-heating, resulting in a roughly $1.5^{\circ} \mathrm{C}$ warm bias at the $0^{\circ} \mathrm{C}$ calibration point. The model fit propagates this bias at $0^{\circ} \mathrm{C}$ to all other temperatures (except for the $-45^{\circ} \mathrm{C}$ and $-79^{\circ} \mathrm{C}$ calibration points, and very small errors between these two calibration points), which leads to a cold bias of up to $0.21^{\circ} \mathrm{C}$ at $-90^{\circ} \mathrm{C}$. In order to account for the self-heating, the following empirical function has been applied to all data prior to 1987 , again only for frostpoint temperatures of $-79^{\circ} \mathrm{C}$ and lower $\left(T_{\mathrm{fp}}\right.$ in $\left.{ }^{\circ} \mathrm{C}\right)$.

$T_{\mathrm{fp}, \text { corr }}=T_{\mathrm{fp}}+\left(0.0203\left(T_{\mathrm{fp}}+61.9\right)\right)^{2}-0.119$ 

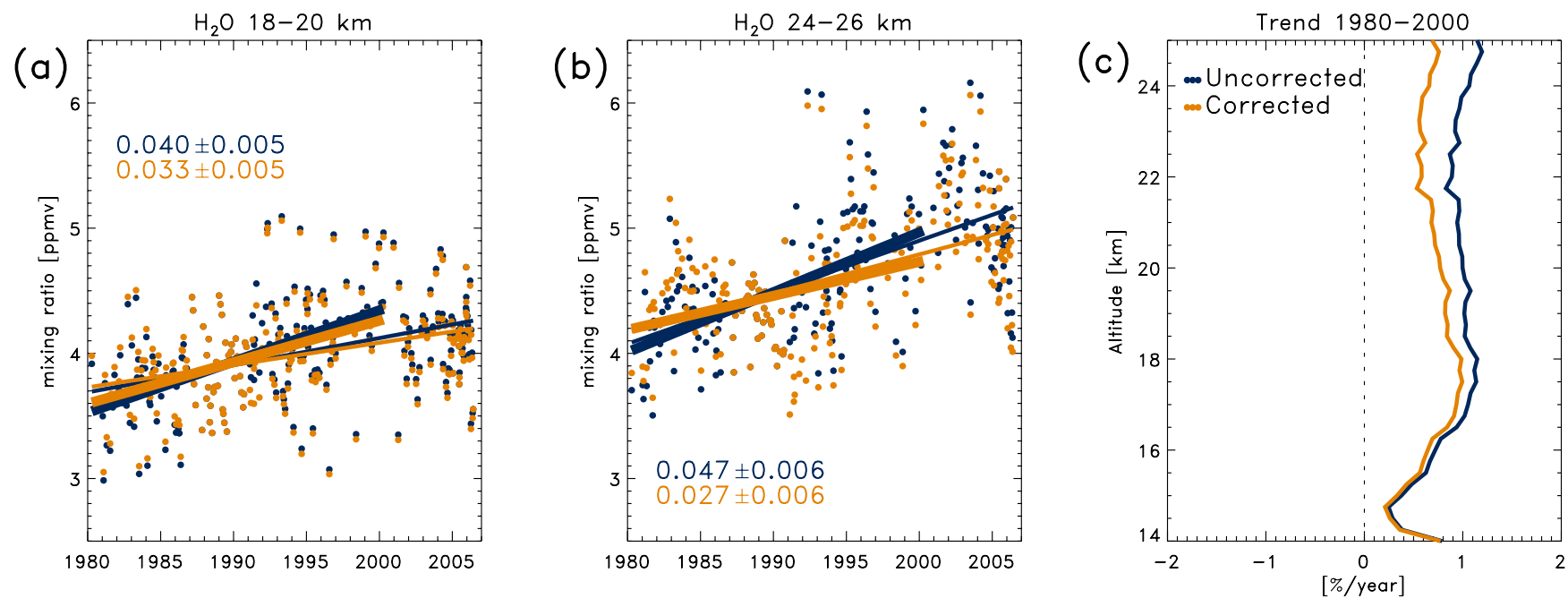

Fig. 1. Linear trend estimates of stratospheric water vapour from NOAA FP measurements. (a) For 18-20 km; (b) for 24-26 km; (c) trend profiles (in percent per year, confidence intervals omitted for clarity). Blue/yellow show uncorrected/corrected data, no correction applied for period 1987-1991. Trends for period 1980-2000 (slope and 2- $\sigma$ uncertainty printed in panels a/b) for comparison with Oltmans et al. (2000). Note trend reduction of up to $40 \%$ due to data correction.

To summarise, previously published NOAA FP measurements of stratospheric water vapour concentrations were biased high after 1991 (first correction) and biased low before 1987 (second correction). Consequently, the corrected data series yield linear trend estimates lower than previously published.

Figure 1 shows the time series and trend estimates as in Oltmans et al. (2000). Trends for the period 1980-2000 between 14 and $25 \mathrm{~km}$ altitude are reduced by up to $40 \%$ and range, after the correction, between 0.2 and $1.05 \% / y r$. The reductions in the trend become larger with increasing altitude, since the corrections are proportional to the frostpoint temperature, which is decreasing with altitude.

\subsubsection{Evaluation of data quality of individual soundings}

In order to better understand the previously reported disagreement between HALOE and NOAA FP, we evaluated the quality of each NOAA FP profile with respect to the following sources of potential errors. First, in some cases the measured frostpoint temperature exhibits large oscillations caused by the instruments feed-back controller. This is often not considered to be a problem, and data may be processed with a low pass filter (Vömel et al., 2007b). However, excessive oscillations may indicate erroneous data. Second, the comparison of data collected during ascent and descent allows some consistency checks. The aforementioned sources for contamination may lead to larger values during ascent than descent, but systematically lower values during ascent may indicate instrumental problems. Profiles that showed excessive mirror oscillations and/or systematically higher values during descent were flagged as being of lower quality, and the subsequent analyses are carried out for both all profiles, as well as for only those of higher quality.

Note that the criterion of the maximum mirror oscillation level is subjectively chosen. However, the screening applied here is based on a priori knowledge of factors that may indicate lower data quality, and does not filter the data towards a subjectively chosen "correct water vapour concentration".

Table 1 provides the number of retrieved soundings in each year together with the number of higher quality soundings. Soundings before 1991 were manually extracted from chart recorder strips. The original recorder strips no longer exist, and a screening as described above is therefore not possible for data before 1991. A total of 44 out of 191 soundings were classified to be of lower quality. A larger fraction of soundings does not meet the quality screening criterion in the late 1990s. Unfortunately, this reduces the number of high quality soundings in the years just before the observed "drop" of water vapour concentrations in 2000/2001, with consequences for the trend estimates (see below).

Figure 2 shows the time series of measurements averaged in the layers of 380-420 and 580-620 K potential temperature. Generally, the lower quality measurements (green) fall within the range of the higher quality measurements (black). However, the 12-month moving averages between the two datasets differ particularly in the years around the year 2000 . Despite the newly applied corrections, the previously noted (Randel et al., 2006) sytematic differences to the HALOE measurements (orange) remain. 


\subsection{HALOE}

HALOE retrieved profiles of various trace gases (including water vapour) based on solar occultation measurements (with about 15 sunrise and 15 sunset events per day) between September 1991 and November 2005. Measurements on any day were made at about the same latitude, but shifted in longitude. The profiles for water vapour range from about 15 to $80 \mathrm{~km}$ altitude and latitudinal coverage was from $60^{\circ} \mathrm{S}$ to $60^{\circ} \mathrm{N}$ over the course of one month. The vertical resolution of the instrument is $1.6 \mathrm{~km}$ at the limb tangent point, and water vapour concentrations are calculated from extinction measurements at 6.61 micrometers. HALOE (version 19) data for profiles near Boulder, Colorado (within $35^{\circ}-45^{\circ} \mathrm{N}$ and $130^{\circ}-80^{\circ} \mathrm{W}$ ) were obtained from the HALOE website (http://haloedata.larc.nasa.gov/download/index.php). Only data from July 1992 onward were used to minimize errors arising from enhanced stratospheric aerosol loading following the eruption of Mt. Pinatubo in 1991. Figure 2 shows the HALOE measurements for the same layers of potential temperature as the NOAA FP measurements. As already noted above, the HALOE and NOAA FP timeseries show systematic differences which will be further quantified below.

\section{Statistical modelling}

The monthly binned $\mathrm{H}_{2} \mathrm{O}$ values $Y_{t}$ with $t$ denoting the number of months from the start of the time series $(t=1 \ldots T)$ are represented in general form as

$Y_{t}=\mu+X_{t}+S_{t}+Z_{t}+N_{t}$

where $\mu$ represents a term for constant offset(s). $X_{t}=\sum_{i}^{n} \omega_{i} X_{i, t}$ represents trend terms with $\omega_{i}$ representing the change per year. $S_{t}$ is the term for the seasonal cycle represented by the annual components: $S_{t}=\alpha \sin (2 \pi t / 12)+\beta \cos (2 \pi t / 12)$ and $Z_{t}$ represents the contribution of the proxies. The term $N_{t}$ stands for the unresolved noise. The noise is modelled as an autoregressive process of first order $N_{t}=N_{t-1}+\epsilon_{t}$, where $\epsilon_{t}$ are independent random variables with zero mean and a common variance $\sigma_{\epsilon}^{2}$.

The QBO affects tropical tropopause temperatures (Baldwin et al., 2001) and as a consequence the stratospheric entry value of water vapour (Giorgetta and Bengtsson, 1999; Fueglistaler and Haynes, 2005). The influence of the QBO is modelled with a combination of equatorial zonal winds at 30 and $70 \mathrm{hPa}$ (Courtesy of B. Naujokat, FU Berlin):

$$
\gamma_{\mathrm{QBO}} Z_{\mathrm{QBO}, t}=\gamma_{30} \mathrm{QBO}_{30, t}+\gamma_{70} \mathrm{QBO}_{70, t}
$$

These two wind time series differ by about $\pi / 2$ in phase and can therefore automatically adjust a variable time lag (Bojkov and Fioletov, 1995).

We use equivalent latitude $\left(\phi_{e q}\right)$ (Sobel et al., 1997) to account for variability associated with stratospheric waves.
Equivalent latitude profiles are calculated based on potential vorticity fields derived from NCEP reanalysis data (Kalnay et al., 1996, obtained from their web site at http://www.cdc. noaa.gov/). More precisely, the proxy is the difference between $\phi_{e q}$ of the measurement and the latitude of Boulder $\left(\phi_{0}=40^{\circ} \mathrm{N}\right)$

$Z_{\phi_{e q}, t}=\phi_{e q, t}-\phi_{0}$.

We find that neither the QBO nor the equivalent latitude proxy for the observations over Boulder shows a trend for the full period 1981-2006, or the period 1992-2005 (comparison with HALOE). Hence, these terms cannot contribute to a trend in water vapour over these periods.

A simple linear trend calculation may be obtained from a regression model of the form

$$
\begin{aligned}
Y_{t}= & \mu+\omega_{1} X_{1, t}+ \\
& S_{t}+\gamma_{\mathrm{QBO}} Z_{\mathrm{QBO}, t}+\gamma_{\phi_{e q}} Z_{\phi_{e q}, t}+N_{t}
\end{aligned}
$$

where $\mu$ is a constant offset, $X_{1, t}=t / 12$ and $\omega_{1}$ is the trend per year. A better representation of the observations may be obtained with a statistical model that accounts for the drop observed around 2001:

$$
\begin{aligned}
Y_{t}= & \mu_{1}+\delta \mu_{2}+\omega_{1} X_{1, t}+\omega_{2} X_{2, t}+ \\
& S_{t}+\gamma_{Q B O} Z_{\mathrm{QBO}, t}+\gamma_{\phi_{e q}} Z_{\phi_{e q}, t}+N_{t}
\end{aligned}
$$

where $\mu_{1}$ is again a constant offset and $\mu_{2}$ is

$\mu_{2}= \begin{cases}0 & t<T^{*} \\ 1 & t \geq T^{*}\end{cases}$

where $T^{*}$ is the time of the discontinuity $\delta . X_{1, t}$ is $t / 12$ and $X_{2, t}$ takes the form

$X_{2, t}= \begin{cases}0 & t<T^{*} \\ \left(t-T^{*}\right) / 12 & t \geq T^{*}\end{cases}$

$X_{2, t}$ is 0 up to the date of trend change $T^{*}$, and increases linearly after that, so that $\omega_{2}$ is the departure from the trend $\omega_{1}$ after $T^{*}$. The trend estimator before the date of change $T^{*}$ is $\omega_{1}$, after $T^{*}$ it is $\omega_{1}+\omega_{2}$ (see Reinsel et al. (2002) for details of a regression analysis using a term like $X_{2, t}$ ). $T^{*}$ is taken as January 2001. (This date is motivated by the results of the analysis of Randel et al. (2006); but by no means implies that the drop occurred exactly at this date. Statistical analyses with dates shifted by a few months yield the same conclusions as those presented below.)

All data are analysed on isentropic surfaces (measurements interpolated onto isentropes every $10 \mathrm{~K}$ ) in the range of 380-640 K (i.e. in the stratospheric "overworld"; Holton et al., 1995). The analysis for NOAA FP data is made separately for the periods 1981-2006 and for 1992-2005 (to allow direct comparison with HALOE data). Due to limited data, we refrain from presenting seasonally resolved trends and variability. 


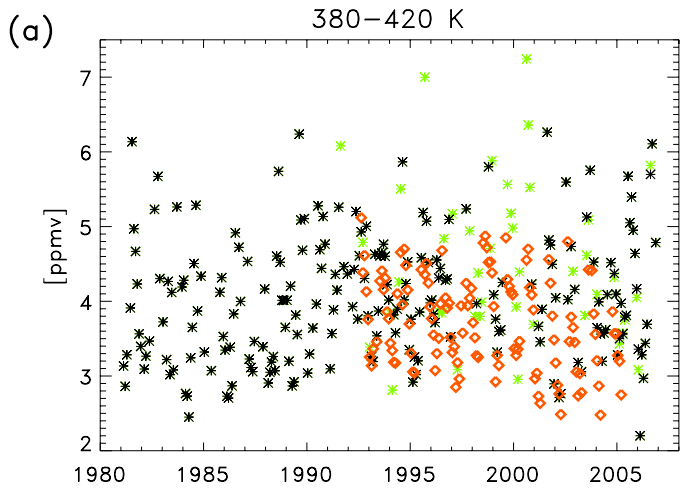

(b)
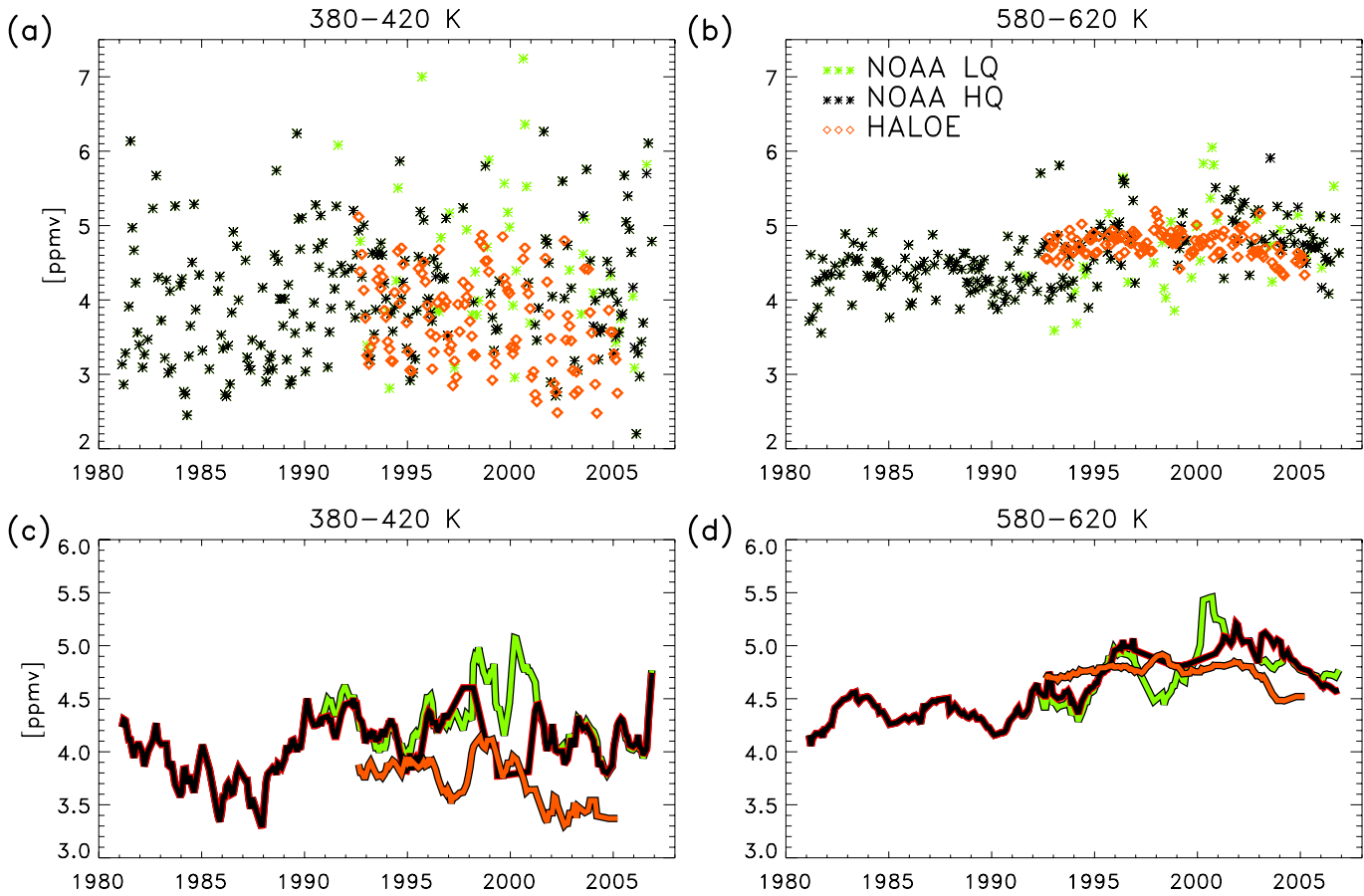

Fig. 2. Water vapour measurements averaged over $380-420 \mathrm{~K}$ (a/c) and $580-620 \mathrm{~K}$ (b/d) potential temperature. Upper plots (a/b) show observations from HALOE (orange) and NOAA frostpoint (separated into "higher quality" (black) and "lower quality" (green) measurements). Lower plots (c/d) show 12-month running mean of the data shown in $(\mathrm{a} / \mathrm{b})$, green curve based on all NOAA FP measurements.

Table 1. The number of NOAA FP soundings by year. For the years 1991 to 2006 the total number is given (All) as well as the number of higher quality soundings (HQ). The high number of measurements in 2005 is a result of the development of the new Cryogenic Frostpoint Hygrometer (CFH) at the University of Colorado (Vömel et al., 2007a).

\begin{tabular}{|c|c|c|c|c|c|c|c|c|c|c|c|c|c|c|c|c|}
\hline & 1980 & 1981 & 1982 & 1983 & 1984 & 1985 & 1986 & 1987 & 1988 & 1989 & 1990 & & & & & \\
\hline All & 1 & 11 & 6 & 9 & 10 & 6 & 10 & 7 & 12 & 12 & 9 & & & & & \\
\hline & 1991 & 1992 & 1993 & 1994 & 1995 & 1996 & 1997 & 1998 & 1999 & 2000 & 2001 & 2002 & 2003 & 2004 & 2005 & 2006 \\
\hline All & 10 & 11 & 13 & 12 & 13 & 13 & 4 & 9 & 9 & 8 & 8 & 9 & 8 & 18 & 30 & 16 \\
\hline HQ & 9 & 10 & 12 & 8 & 12 & 10 & 1 & 1 & 6 & 1 & 8 & 8 & 5 & 16 & 26 & 14 \\
\hline
\end{tabular}

\section{Results: variability and trends}

\subsection{Variability}

Figure 3a shows the variability (standard deviation) of the time series, and panel (b) shows the fraction of explained variance $\left(R^{2}\right)$ by the regression model. The figure shows that the variability decreases monotonically with height up to about $450 \mathrm{~K}$, and then remains constant up to $640 \mathrm{~K}$ (top level of our analysis). This vertical structure is very similar between HALOE and NOAA FP, but the variability of the NOAA FP measurements (both all data and the higher quality subset) is markedly higher (about $0.2 \mathrm{ppmv}$ ) than that of the HALOE measurements at all levels.
Figure $3 \mathrm{~b}$ shows that the regression model is generally better for the HALOE data and at lower altitudes. Both for HALOE and NOAA FP a substantial fraction of variance remains unexplained by the model. This unexplained variability may be a consequence of physical processes not captured by the model (for example variations in water vapour mixing ratios associated with (vertically) thin filaments) or instrumental uncertainties. Resolving the cause of these residuals, and the differences between the two instruments, is beyond the scope of this paper, but should be a focus of future studies. 

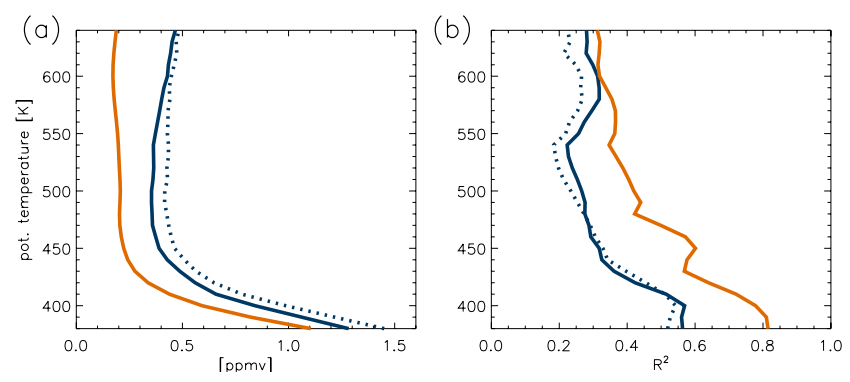

Fig. 3. (a) Standard deviation of the measured water vapour timeseries $\left(\sigma_{\mathrm{H}_{2} \mathrm{O}}\right)$. (b) Fraction of variance $\left(R^{2}\right)$ explained by the regression model (see text, Eq. 6). Orange: HALOE, 1992-2005; blue: NOAA FP 1981-2006 (dotted line: all NOAA FP data, solid line: only higher quality data; see text).
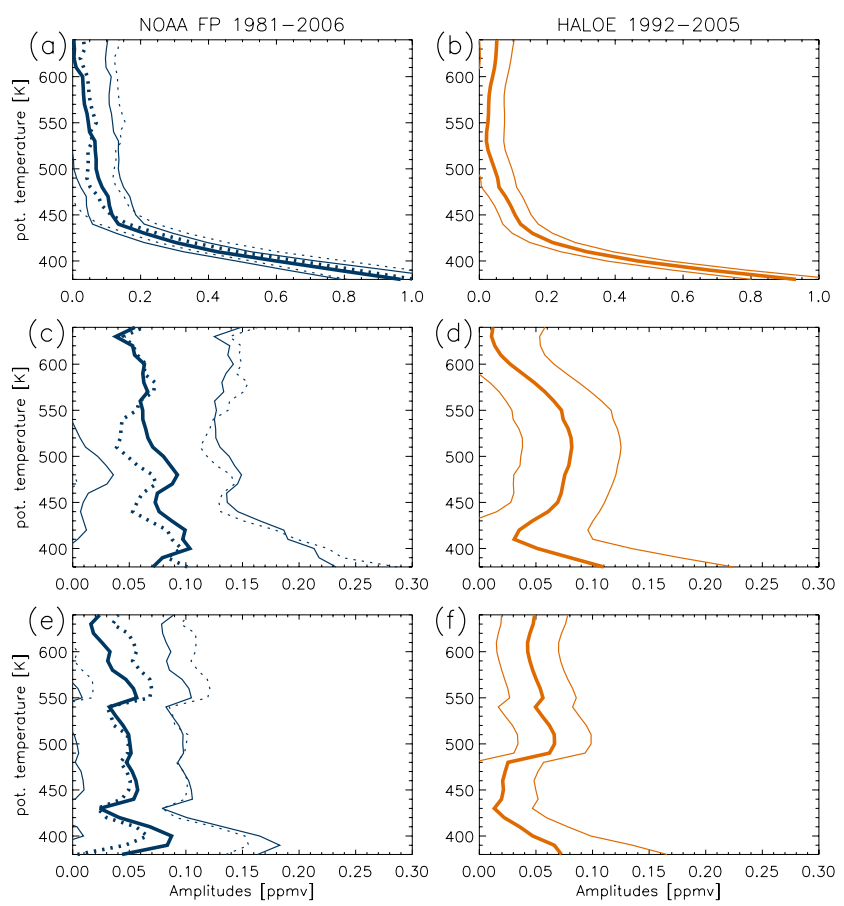

Fig. 4. Amplitudes (thick lines) and the 2- $\sigma$ confidence interval (thin lines) of the regression model for NOAA FP (a/c/e; solid line higher quality data, dotted line all data) and HALOE (b/d/f). (Conventions as in Fig. 3.) (a/b) Amplitude of seasonal cycle; (c/d) Amplitude of the QBO proxy; (e/f) Amplitude of the equivalent latitude proxy. Note different scale of abscissa of (a, b) and (c, d, e, f).

\subsubsection{Seasonal cycle}

Figure $4 \mathrm{a}, \mathrm{b}$ shows the amplitudes of the seasonal cycle in the regression model. The amplitude is calculated as the standard deviation of the proxy time series multiplied with its estimated coefficient, i.e. $\mathrm{SD}\left(\alpha \sin \frac{\pi}{6} t+\beta \cos \frac{\pi}{6} t\right)$ is the amplitude of the seasonal component. For the NOAA FP, the amplitude of the annual component is about $1 \mathrm{ppmv}$ at $380 \mathrm{~K}$ and decreases linearly to $0.1 \mathrm{ppmv}$ at $450 \mathrm{~K}$. For HALOE, the decay of the amplitude of seasonal variability is slightly smoother, but overall the profile is very similar to that of the NOAA FP data. The profile of the amplitude of the seasonal cycle illustrates the previously noted change in circulation and transport around $450 \mathrm{~K}$, with rapid meridional mixing and transport up to about $450 \mathrm{~K}$, and fairly isolated tropics above (the "tropical pipe", Plumb (1996)).

\subsubsection{QBO and equivalent latitude}

The variability accounted for by the QBO and by $\phi_{e q}$ is shown in Fig. 4c, d and e, f, respectively. (Note change in scaling of x-axis.) The amplitude of the QBO component in the NOAA FP data is less than $0.1 \mathrm{ppmv}$, and over much of the profile statisticallly not significant (at the 2- $\sigma$ level). HALOE shows similar amplitudes for the QBO component, but a different shape of the profile (values between $450 \mathrm{~K}$ and $600 \mathrm{~K}$ are significant).

Similar to the QBO, the amplitudes of $\phi_{e q}$ are small (less than 0.1 ppmv) in both NOAA FP and HALOE data. Again, the shape of the profiles differs somewhat, but given the minor role played by these proxies, further analysis of these differences is not warranted.

\subsection{Linear trends}

Linear trends derived from Eq. (6) are shown in Fig. 5. The trend estimates based on NOAA FP (higher quality) data for the period 1981-2006 show statistically significant trends (with their $2-\sigma$ uncertainties) ranging from $0.012 \pm 0.005$ to $0.031 \pm 0.005 \mathrm{ppmv} / \mathrm{yr}$. For the period 1992-2005, the NOAA FP trends are not significant below about $500 \mathrm{~K}$. For both periods, the trends based on all NOAA FP profiles are generally slightly higher than those based on the higher quality profiles only. In contrast to the NOAA FP data, HALOE data for the period 1992-2005 show negative trends that peak at $420 \mathrm{~K}$ with $-0.04 \pm 0.02 \mathrm{ppmv} / \mathrm{yr}$, but the tendency towards more positive trends with height is similar to that found in the NOAA FP data.

Finally, we note that although the variance of the high quality data of the NOAA FP is smaller than that of all measurements, the fraction of explained variance, the amplitudes of the seasonal cycle, QBO and equivalent latitude proxy, as well as the linear trends all are very similar (and indeed in most cases statistically not significantly different) between the two datasets. Hence, for many applications a screening of the NOAA data as applied here may not be necessary. However, larger differences between the two datasets exist in the late 1990s, and consequently in their representation of the changes observed around 2000/2001 (discussed below).

\subsection{Decrease in 2001}

Global mean deseasonalised water vapour anomalies from HALOE (at $82 \mathrm{hPa}$ ) show a rather fast decrease at the beginning of 2001 (Randel et al., 2006). Linear trends from 

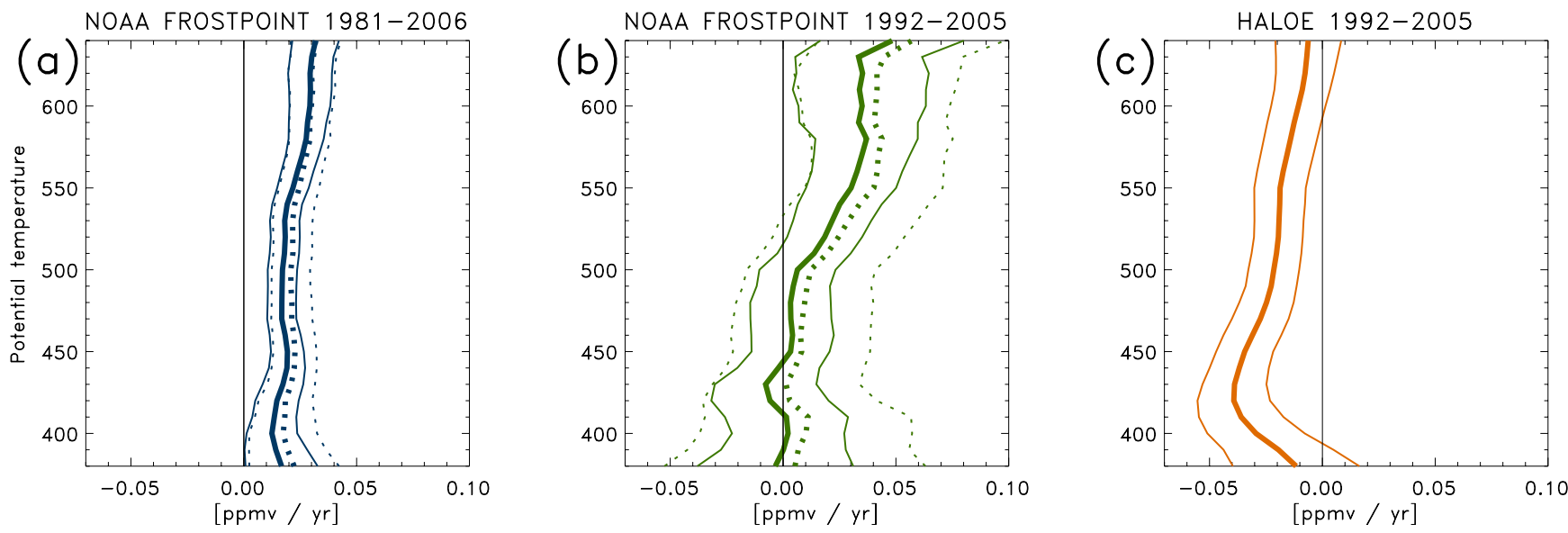

Fig. 5. Trends (thick lines) with the $2-\sigma$ confidence intervals (thin lines) calculated with Eq. (6) for (a) NOAA FP 1981-2000; (b) NOAA FP 1992-2005; (c) HALOE 1992-2005. Same conventions for color/linestyles as in Figs. 3/4.

1981-2006, and for the shorter period 1992-2005, with no distinction between the periods before and after 2001, may not provide an appropriate description of the changes in stratospheric water vapour. Hence we use a regression model as described in Eq. (7), which calculates trends before and after 2001 separately. Figure 6 shows observations and regression fit together with the trend estimates for both periods. For the layer $380-420 \mathrm{~K}$ (note analysis here is done for layer averages, not for data interpolated onto single isentropic levels as before), the model yields slightly increasing water vapour concentrations before and after 2001, and a drop of $0.2 \pm 0.6 \mathrm{ppmv}$ and $0.45 \pm 0.0008 \mathrm{ppmv}$ for NOAA FP and HALOE, respectively. The drop in the statistical model for the NOAA FP data is statistically not significant (at the $2 \sigma$-level), but is highly significant for the HALOE data. Given the larger variability of the NOAA FP measurements, this difference may not be surprising. Perhaps more important, however, is that the drop in the two observational timeseries is at least qualitatively consistent.

For the layer 580-620 K, both NOAA FP and HALOE show positive trends before 2001, and negative trends afterwards. In this layer, the change in 2001 is an insignificant decrease of $-0.13 \pm 1.12 \mathrm{ppmv}$ for NOAA FP, whereas for HALOE it is an insignificant increase of $0.04 \pm 0.08$ ppmv. Water vapour concentrations at higher altitudes show a smoother turnaround compared to the sharp drop at lower altitudes. This difference can be attributed to the broader distribution of age of air (see e.g. Waugh and Hall, 2002) at higher altitudes, and a statistical model with the possibility of a "drop" may not be necessary at these levels.

The results of our statistical analysis support the conclusion of Randel et al. (2006) that stratospheric water vapour entry mixing ratios experienced a "drop" around 2000/2001, rather than a "trend reversal". At present, $\mathrm{H}_{2} \mathrm{O}$ in the stratosphere below $\approx 450 \mathrm{~K}$ does not appear to decrease further after 2001. In fact, the linear trend estimates suggest a statis-
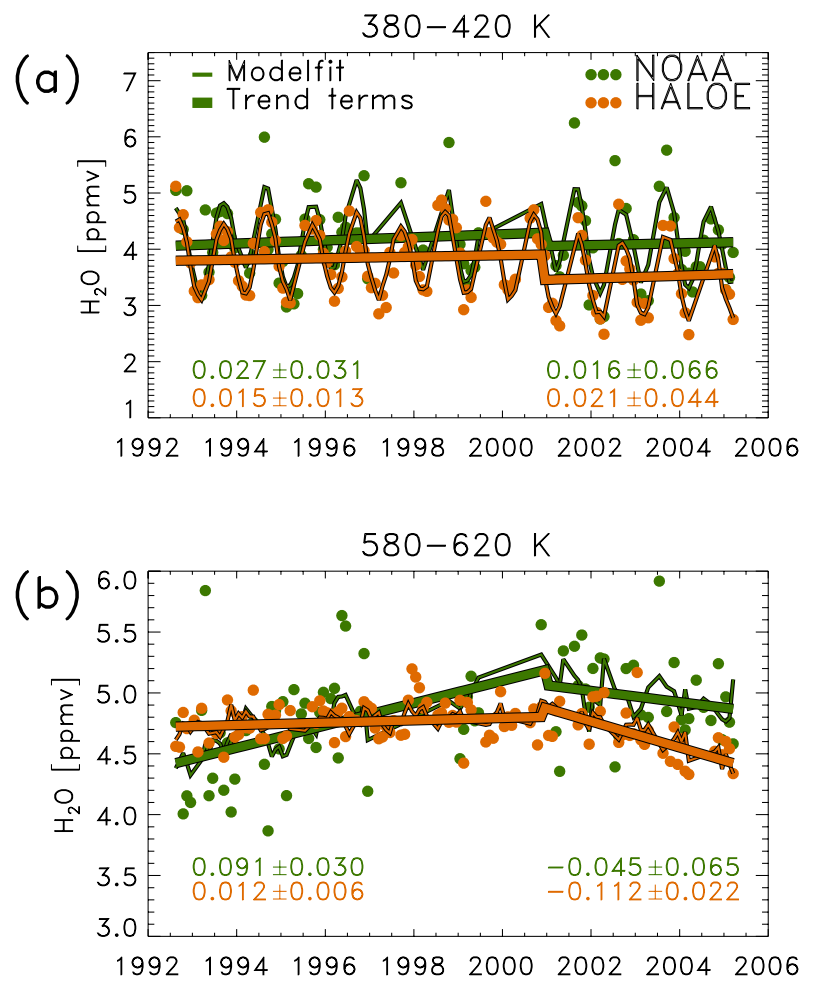

Fig. 6. Observations and regression fit derived from Eq. (7) at (a) $380-420 \mathrm{~K}$ and (b) $580-620 \mathrm{~K}$. Thin lines denote the regression fit and thick lines the trend terms (corresponding to $\mu_{1}+\delta \mu_{2}+\omega_{1} X_{1, t}+\omega_{2} X_{2, t}$ in Eq. 7). Trend estimates (in ppmv/yr) before and after January 2001 are shown with their $2 \sigma$ uncertainty in the corresponding colours. Results for NOAA FP are shown for the higher quality data subset.

tically insignificant increase since 2001 of similar order to that before 2001. However, both trend estimates are based on relatively short periods that leads to large uncertainties 


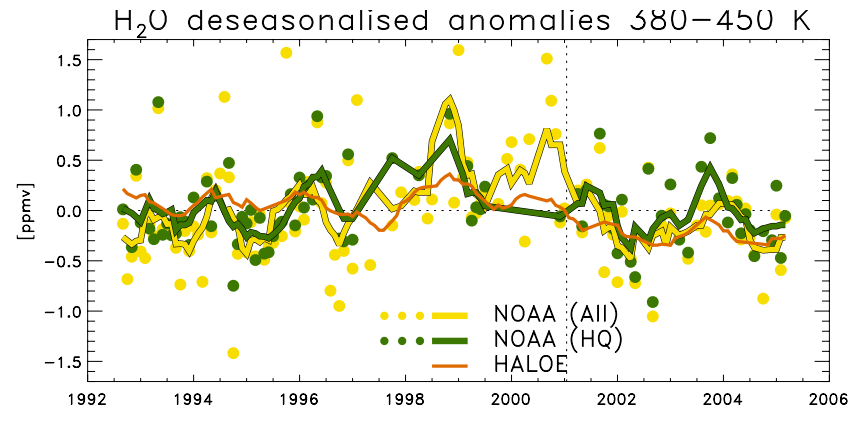

Fig. 7. Deseasonalised anomalies of $\mathrm{H}_{2} \mathrm{O}$ between 380 and $450 \mathrm{~K}$ with a 6 month moving average. For NOAA FP, yellow dots and curve are based on the entire data set; whereas the green dots and line are based on the higher quality soundings only. The moving average of HALOE is shown in orange (no data points). The vertical dotted line indicates January 2001.

(particularly for the period 2001-2005). The exact magnitude of the trends thus depends also to some extent on the "start/end time" of the time series.

Because many NOAA FP profiles in the years before the drop were rated as being of lower quality, the trend estimates based on all NOAA FP profiles yield different results. Figure 7 shows the time series of deseasonalized water vapour anomalies of the layer 380-420 K for all (yellow) and the high quality (green) NOAA FP measurements, and those from HALOE (red). Compared to the higher quality data set, trends calculated with all NOAA FP measurements (not shown) are more positive for the period before 2001, and more negative after 2001. Also, the drop in 2001 is larger.

\section{Discussion of the long-term trend}

Variability and trends in stratospheric water vapour over Boulder may be caused by changes in the fraction of oxidised methane (which depends mainly on the age of air distribution), and changes in the entry mixing ratios of methane and water vapour. Of particular interest is the question whether observations suggest a long-term trend in the water vapour entry mixing ratios, which could indicate important changes in transport of water, and possibly other trace gas species, into the stratospheric overworld. More specifically, the question is whether stratospheric water vapour shows variations and trends that cannot be explained by temperature variations in the vicinity of the tropopause.

Here, we use a simple model to predict water vapour mixing ratios over Boulder based on water vapour and methane entry mixing ratios. Due to relatively short time series and the low number of NOAA FP profiles, we use a simple forward model as previously used by Fueglistaler and Haynes (2005) instead of a regression analysis. (Results and conclusions obtained from a regression analysis were very similar to those presented below.)

\subsection{Model}

Following Fueglistaler and Haynes (2005) we write water vapour in the stratospheric overworld $\left(\left[\mathrm{H}_{2} \mathrm{O}\right]_{\mathrm{o}}\right)$ as

$\left[\mathrm{H}_{2} \mathrm{O}\right]_{\mathrm{o}}=\left[\mathrm{H}_{2} \mathrm{O}\right]_{\mathrm{CH}_{4}}+\left[\mathrm{H}_{2} \mathrm{O}\right]_{\left[\mathrm{H}_{2} \mathrm{O}\right]_{\mathrm{e}}}$

The contribution of the methane oxidation to $\mathrm{H}_{2} \mathrm{O}$ at a given altitude is

$\left[\mathrm{H}_{2} \mathrm{O}\right]_{\mathrm{CH}_{4}}(\theta, t)=\alpha\left(\left[\mathrm{CH}_{4}\right]_{\mathrm{e}}(t-\tau(\theta))-\left[\mathrm{CH}_{4}\right](\theta, t)\right)$

where $\alpha$ is $\approx 2$ (Le Texier et al., 1988). $\left[\mathrm{CH}_{4}\right]_{\mathrm{e}}$ is a 2 nd order polynomial fit to tropospheric global mean $\mathrm{CH}_{4}$ (see Dlugokencky et al. (2003) and references therein) and $\left[\mathrm{CH}_{4}\right]$ is a 2nd order fit to stratospheric $\mathrm{CH}_{4}$ measurements at midlatitudes (Rohs et al., 2006). $\tau$ is the mean age of midlatitude stratospheric air. Midlatitude stratospheric water vapour that can be accounted for by $\left[\mathrm{H}_{2} \mathrm{O}\right]_{\mathrm{e}}$ is obtained from

$$
\begin{aligned}
& {\left[\mathrm{H}_{2} \mathrm{O}\right]_{\left[\mathrm{H}_{2} \mathrm{O}\right]_{\mathrm{e}}}(\theta, t)=} \\
& \quad \int_{0}^{6}\left[\mathrm{H}_{2} \mathrm{O}\right]_{\mathrm{e}}(t-\tau) \cdot w(t-\tau) \cdot h(\theta, \tau) d \tau
\end{aligned}
$$

where $w(t-\tau)$ is a weighting function accounting for the seasonally varying troposphere to stratosphere upward mass flux in the tropics (Holton, 1990). The age spectra of stratospheric air $(h(\tau))$ were obtained from Andrews et al. (2001) and from Waugh and Hall (2002). These age spectra were truncated at 6 years and are kept constant over the period of interest here.

We restrict the timeseries of water vapour entry mixing ratios given by Fueglistaler and Haynes (2005) to the period where ERA-40 (tropical tropopause) temperatures do not show larger deviations (that is, about a $1 \mathrm{~K}$ drift over a 5 year period) from radiosonde measurements. As a test of the self consistency of the model and water vapour observations, we also analyse results obtained from a calculation where we replace $\left[\mathrm{H}_{2} \mathrm{O}\right]_{\mathrm{e}}$ in Eq. (12) with tropical $\left(30^{\circ} \mathrm{S}-30^{\circ} \mathrm{N}\right) \mathrm{H}_{2} \mathrm{O}$ at $400 \mathrm{~K}$ as measured by HALOE $\left(\left[\mathrm{H}_{2} \mathrm{O}\right]_{400}\right)$.

\subsection{Results}

Figure 8 shows observations (green for NOAA FP, orange for HALOE) and model predictions (black, red for the model based on HALOE $\left[\mathrm{H}_{2} \mathrm{O}\right]_{400}$ ) for the layers of $410-450 \mathrm{~K}$, $440-480 \mathrm{~K}$ and $600-620 \mathrm{~K}$. Generally, the model yields better agreement with HALOE than with NOAA FP for all levels. The model predictions based on HALOE tropical measurements are very similar to those based on ERA-40 circulation and temperature presented by Fueglistaler and Haynes (2005). However, we note that the model predictions tend to systematically overestimate/underestimate observations at the beginning/end of the timeseries.

Figure 9 shows the differences between the model predictions and the observations with a linear trend fit. The magnitude of the residual trend between model prediction and 

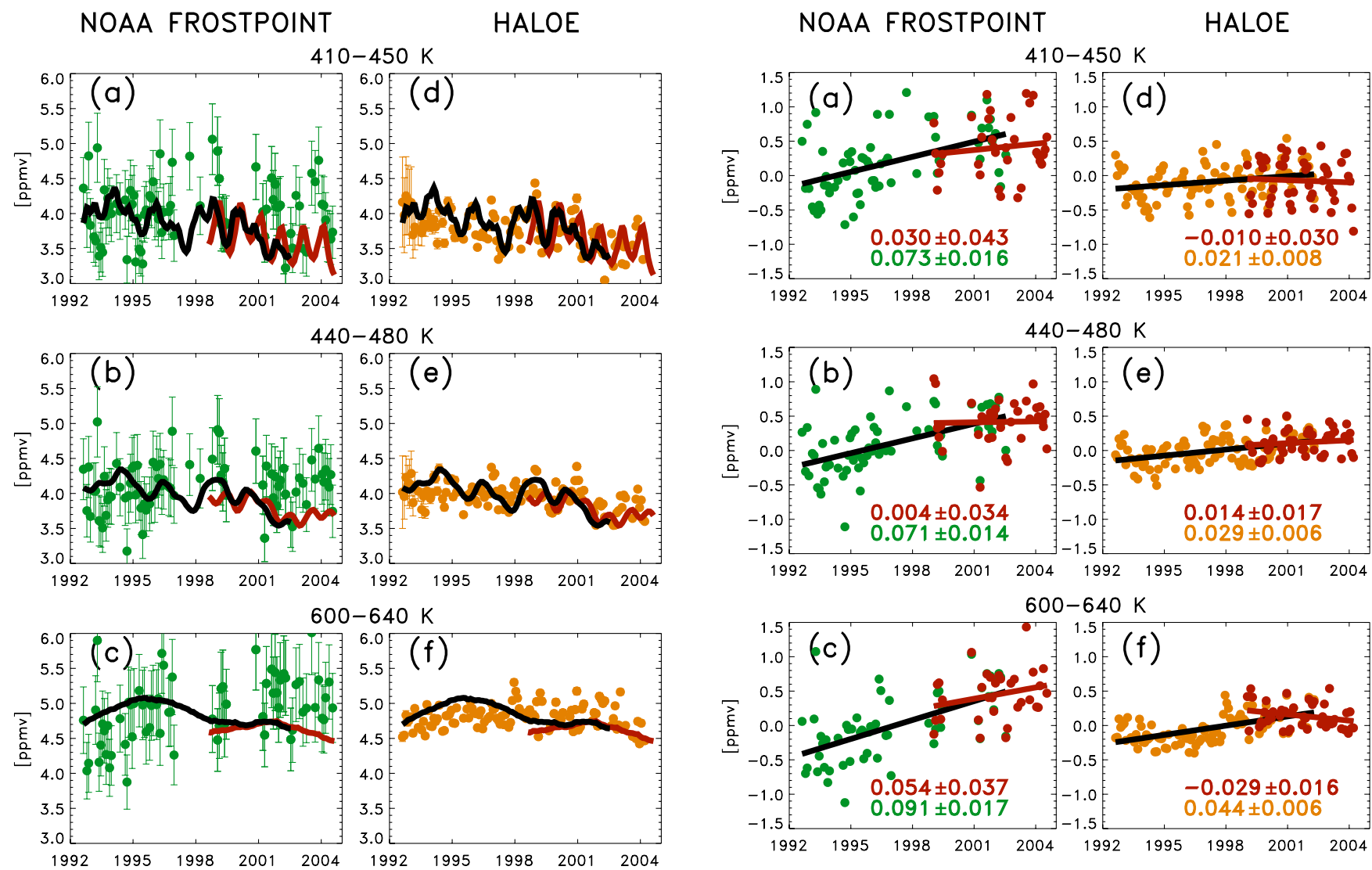

Fig. 8. Observation and model as in Eq. (10) for the layers (a, d) $410-450 \mathrm{~K}$, (b, e) $440-480 \mathrm{~K}$, (c, f) $600-640 \mathrm{~K}$; for NOAA FP $(\mathrm{a}, \mathrm{b}, \mathrm{c})$ and HALOE $(\mathrm{d}, \mathrm{e}, \mathrm{f})$. The black line shows the " $\left[\mathrm{H}_{2} \mathrm{O}\right]_{\mathrm{e}}$ model" estimate and the red line shows the model estimate using HALOE measurements in the tropics at $400 \mathrm{~K}$ (see text). Note that for HALOE, error bars are smaller than the dots, except for low altitudes in the years following the eruption of Mt. Pinatubo.

NOAA FP is larger than the trend in the residual between the model prediction and HALOE data. At $410-450 \mathrm{~K}$, for the NOAA FP the trend in the residual is $0.073 \pm 0.016 \mathrm{ppmv} / \mathrm{yr}$, and at $600-640 \mathrm{~K}$ it is $0.091 \pm 0.017 \mathrm{ppmv} / \mathrm{yr}$. For the HALOE data, the trends in the residual for these layers are $0.021 \pm 0.08 \mathrm{ppmv} / \mathrm{year}$ and $0.044 \pm 0.044 \mathrm{ppmv} / \mathrm{yr}$. The predictions based on HALOE tropical measurements yield a trend in the residual with a magnitude that tends to be smaller than that of the model predictions for entry mixing ratios (but note that we cannot calculate the trends for the same periods).

The fact that the model predictions based on HALOE tropical measurements do not give perfect agreement with the HALOE measurements over Boulder may indicate that the age spectrum, and hence the fraction of oxidised methane does not remain constant. It has been suggested that the stratospheric circulation increases with increasing greenhouse gas concentrations (e.g. Butchart and Scaife, 2001; Austin and Li, 2006), but its impact over the short periods considered here is presumably marginal.

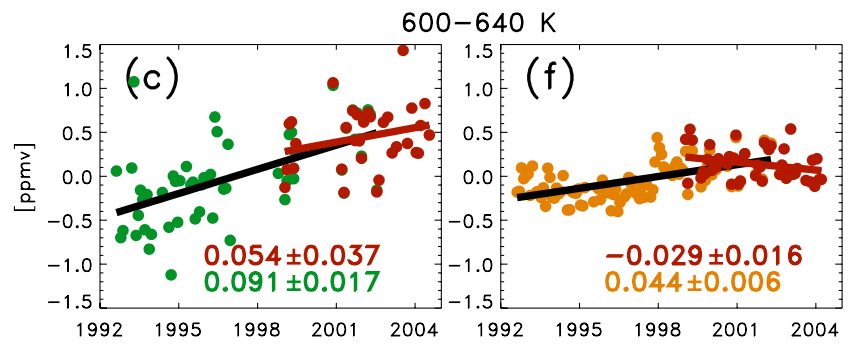

Fig. 9. Residual between model prediction and observations. Figure layout as in Fig. 8. Green: residuals of model results based on $\left[\mathrm{H}_{2} \mathrm{O}\right]_{\mathrm{e}}$ from Fueglistaler and Haynes (2005); red: residuals of model results based on tropical HALOE measurements at $400 \mathrm{~K}$. Linear trends and 2- $\sigma$ uncertainty printed in each panel.

The fact that the sign of the residual trend is the same for both HALOE and NOAA FP may be seen as an indicator that the linear trend of the $\left[\mathrm{H}_{2} \mathrm{O}\right]_{\mathrm{e}}$ timeseries has a bias. When converted to temperature, that bias is of order $2 \mathrm{~K} /$ decade for the NOAA FP measurements, and less than $1 \mathrm{~K} /$ decade for the HALOE measurements. In order to quantify a trend in $\left[\mathrm{H}_{2} \mathrm{O}\right]_{\mathrm{e}}$ that is not controlled by the processes considered by Fueglistaler and Haynes (2005), one would need (i) time series of observations from different instruments that yield consistent trend estimates, and (ii) a reanalysis dataset with residual trends in tropopause temperatures that are much smaller than $1 \mathrm{~K} /$ decade. Clearly, the ERA-40 temperatures do not satisfy this requirement.

\section{Conclusions}

We have presented an analysis of the NOAA FP water vapour measurements in the stratospheric overworld over Boulder, Colorado. We have applied two corrections for newly identifed biases in the measurements, and quality-screened 
all observations. The corrected measurements show linear trends that are up to $40 \%$ smaller than those previously published. For the period 1980-2000, the new linear trend estimates are $0.33 \pm 0.05 \mathrm{ppmv} / \mathrm{yr}$ for $18-20 \mathrm{~km}$, and $0.027 \pm 0.006 \mathrm{ppmv} / \mathrm{yr}$ for $24-26 \mathrm{~km}$. Previously noted systematic differences (larger variability, larger linear trends) to HALOE remain for the corrected NOAA FP data. This larger variability could reflect true variability on scales not resolved by HALOE, but likely the differences arise from differences in the measurement techniques. Averaging the NOAA FP data with a kernel representing the vertical HALOE weighting function may be useful to better understand the causes of these differences, but it is not expected that such an averaging would substantially alter the results and conclusions of this paper.

Analysis with a statistical model showed that most of the variability is associated with seasonal variations, and that the QBO and equivalent latitude play only a minor role. Similar to HALOE, the NOAA FP data show around 2000/2001 a sudden drop of water vapour concentrations at the base of the stratospheric overworld, where rapid quasi-isentropic transport ensures fast communication of changes in water vapour entry mixing ratios to the middle latitudes. Consequently, a linear trend fit over the period 1980-2006 may not be an appropriate representation of the data. Hence, we applied a statistical model that allows for a discontinuity (in January 2001). This model yields the following results for the layer $380-420 \mathrm{~K}$ potential temperature: a linear trend of $0.027 \pm 0.031 \mathrm{ppmv} / \mathrm{yr}$ for the period 1992-2001, a linear trend of $0.016 \pm 0.066 \mathrm{ppmv} / \mathrm{yr}$ for the period 20012006 , and a drop of $-0.2 \pm 0.6 \mathrm{ppmv}$ in 2001 . Water vapour concentrations thus tend to increase over both periods when viewed separately, but the trends are statistically not significantly different from zero. The drop in 2000/2001 is also statistically not significant in the NOAA FP data, but is consistent with the results of the same model applied to HALOE data, which give a statistically highly significant drop of $0.45 \pm 0.0008$ ppmv.

Higher up in the stratosphere, the discontinuity in entry mixing ratios is masked by the broad age spectrum of air masses that acts as a low-pass filter. The observed pattern of change in water vapour concentrations indicates that the change arises from processes that affect water vapour concentrations at entry into the stratosphere, and we emphasize that the water vapour timeseries shows a discontinuity rather than a "trend reversal". The observed discontinuity as well as the substantial reduction of linear trend estimates indicate that great caution should be used with respect to predictions of the impact of stratospheric water vapour on radiative forcing and stratospheric temperature and ozone in the coming decades.

We have tried to quantify a residual trend in stratospheric water vapour entry mixing ratios from the difference between NOAA FP and HALOE middle latitude measurements to values predicted from a simple model. The model assumes con- stant age of air over time, and $\left[\mathrm{H}_{2} \mathrm{O}\right]_{\mathrm{e}}$ is based on large scale temperatures and circulation in the vicinity of the tropical tropopause (Fueglistaler and Haynes, 2005). The residual trends (observation minus model) are much larger for NOAA FP than HALOE, but are positive for both datasets.

A reliable quantification of trends in $\left[\mathrm{H}_{2} \mathrm{O}\right]_{\mathrm{e}}$ from the NOAA FP and HALOE middle latitude measurements due to processes not considered by Fueglistaler and Haynes (2005) is currently not possible due to the large difference between the residual to NOAA FP and to HALOE data. Moreover, the model predictions of $\left[\mathrm{H}_{2} \mathrm{O}\right]_{e}$ would require a reanalysis data set with erroneous drifts in tropical tropopause temperatures that are substantially smaller than $1 \mathrm{~K} /$ decade; a requirement currently not fulfillled by either ERA-40 or the NCEP reanalyses. In the near future, temperature retrievals from GPS may provide timeseries of temperature with sufficient temporal stability. Our analysis demonstrates the need for ongoing efforts to obtain long and continous time series of stratospheric water vapour.

Acknowledgements. We would like to thank J. Harris, E. Weatherhead and K. Rosenlof for discussions during the course of this work. We also thank three anonymous reviewers for their constructive and helpful reviews.

Edited by: T. Röckmann

\section{References}

Andrews, A. E., Boering, K. A., Wofsy, S. C., Daube, B. C., Jones, D. B., Alex, S., Loewenstein, M., Podolske, J. R., and Strahan, S. E.: Empirical age spectra for the midlatitude lower stratosphere from in situ observations of $\mathrm{CO}_{2}$ : Quantitative evidence for a subtropical "barrier" to horizontal transport, J. Geophys. Res., 106, 10 257-10 274, doi:10.1029/2000JD900703, 2001.

Austin, J. and Li, F.: On the relationship between the strength of the Brewer-Dobson circulation and the age of stratospheric air, Geophys. Res. Lett., 33, 17 807, doi:10.1029/2006GL026867, 2006.

Austin, J., Wilson, J., Feng, L., and Vömel, H.: Evolution of water vapor concentrations and stratsophereic age of air in coupled chemistry-climate model simulations, J. Atmos. Sci., 64, 905921, doi:10.1175/JAS3866.1, 2007.

Baldwin, M. P., Gray, L. J., Dunkerton, T. J., Hamilton, K., Haynes, P. H., Randel, W. J., Holton, J. R., Alexander, M. J., Hirota, I., Horinouchi, T., Jones, D. B. A., Kinnersley, J. S., Marquardt, C., Sato, K., and Takahashi, M.: The quasi-biennial oscillation, Rev. Geophys., 39, 179-230, doi:10.1029/1999RG000073, 2001.

Bojkov, R. D. and Fioletov, V. E.: Estimating the global ozone characteristics during the last 30 years, J. Geophys. Res., 100, 16537-16552, doi:10.1029/95JD00692, 1995.

Butchart, N. and Scaife, A. A.: Removal of chlorofluorocarbons by increased mass exchange between the stratosphere and troposphere in a changing climate, Nature, 410, 799-802, 2001.

Chiou, E. W., Thomason, L. W., and Chu, W. P.: Variability of Stratosphereric Water Vapor Inferred from SAGE II, HALOE, and Boulder (Colorado) Balloon Measurements, J. Climate, 19(16), 4121-4133, doi:10.1175/JCLI3841.1, 2006. 
Dlugokencky, E. J., Houweling, S., Bruhwiler, L., Masarie, K. A., Lang, P. M., Miller, J. B., and Tans, P. P.: Atmospheric methane levels off: Temporary pause or a new steady-state?, Geophys. Res. Lett., 30, 1992, doi:10.1029/2003GL018126, 2003.

Dvortsov, V. L. and Solomon, S.: Response of the stratospheric temperatures and ozone to past and future increases in stratospheric humidity, J. Geophys. Res., 106, 7505-7514, doi:10. 1029/2000JD900637, 2001.

Forster, P. M. d. F. and Shine, K. P.: Assessing the climate impact of trends in stratospheric water vapor, Geophys. Res. Lett., 29, 10-1, 2002.

Fueglistaler, S. and Haynes, P. H.: Control of interannual and longer-term variability of stratospheric water vapor, J. Geophys. Res., 110, 24 108, D24 108, doi:10.1029/2005JD006019, 2005.

Fueglistaler, S., Bonazzola, M., Haynes, P. H., and Peter, T.: Stratospheric water vapor predicted from the Lagrangian temperature history of air entering the stratosphere in the tropics, J. Geophys. Res., 110, D08 107, doi:10.1029/2004JD005516, 2005.

Giorgetta, M. A. and Bengtsson, L.: Potential role of the quasibiennial oscillation in the stratosphere-troposphere exchange as found in water vapor in general circulation model experiments, J. Geophys. Res., 104, 6003-6020, doi:10.1029/1998JD200112, 1999.

Holton, J. R.: On the Global Exchange of Mass between the Stratosphere and Troposphere., J. Atmos. Sci., 47, 392-396, 1990.

Holton, J. R., Haynes, P. H., McIntyre, M. E., Douglass, A. R., Rood, R. B., and Pfister, L.: Stratosphere-troposphere exchange, Rev. Geophys., 33, 403-439, 1995.

Joshi, M. M. and Shine, K. P.: A GCM Study of Volcanic Eruptions as a Cause of Increased Stratospheric Water Vapor., J. Climate, 16, 3525-3534, 2003.

Kalnay, E., Kanamitsu, M., Kistler, R., Collins, W., Deaven, D., Gandin, L., Iredell, M., Saha, S., White, G., Woollen, J., Zhu, Y., Leetmaa, A., Reynolds, B., Chelliah, M., Ebisuzaki, W., Higgins, W., Janowiak, J., Mo, K. C., Ropelewski, C., Wang, J., Jenne, R., and Joseph, D.: The NCEP/NCAR 40-Year Reanalysis Project., B. Am. Meteorol. Soc., 77, 437-472, 1996.

Kley, D., Russell III, J. M., and Philips, C. (Eds.): SPARC assessment of upper tropospheric and stratospheric water vapour, WCRP 113, WMO/TD No. 1043, SPARC Report Nr.2, World Meteorol. Organ., 2000.

Layton, E. C.: Report of the determination of exactness of fit of thermistor to the equations $\log R=A+B /(T+\Theta)$ and $\log R=A+B /(T+\Theta)+C T$, Tech. Rep. 2168, U.S. Army Signal Res. and Dev. Lab, 1961.

Le Texier, H., Solomon, S., and Garcia, R. R.: The role of molecular hydrogen and methane oxidation in the water vapour budget of the stratosphere, Q. J. Roy. Meteorol. Soc., 114, 281-295, 1988.

Notholt, J., Luo, B. P., Fueglistaler, S., Weisenstein, D., Rex, M., Lawrence, M. G., Bingemer, H., Wohltmann, I., Corti, T., Warneke, T., von Kuhlmann, R., and Peter, T.: Influence of tropospheric $\mathrm{SO}_{2}$ emissions on particle formation and the stratospheric humidity, Geophys. Res. Lett., 32, L07 810, doi: 10.1029/2004GL022159, 2005.

Oltmans, S. J.: Measurements of water vapor in the stratosphere with a frost point hygrometer, Measurement and Control in Science and Industry, in: Proceedings of the 1985 International Symposium on Moisture and Humidity, pp. 251-258, Instrument Society of America, Washington, D.C., 1985.
Oltmans, S. J. and Hofmann, D. J.: Increase in lower-stratospheric water vapour at a mid-latitude Northern Hemisphere site from 1981 to 1994 , Nature, 374, 146-149, 1995.

Oltmans, S. J., Vömel, H., Hofmann, D. J., Rosenlof, K. H., and Kley, D.: The increase in stratospheric water vapor from balloonborne, frostpoint hygrometer measurements at Washington, D.C., and Boulder, Colorado, Geophys. Res. Lett., 27, 34533456, doi:10.1029/2000GL012133, 2000.

Plumb, R. A.: A “tropical pipe" model of stratospheric transport, J. Geophys. Res., 101, 3957-3972, doi:10.1029/95JD03002, 1996.

Randel, W. J., Zawodny, J. M., and Oltmans, S. J.: Seasonal variation of water vapor in the lower stratosphere observed in Halogen Occultation Experiment data, J. Geophys. Res., 106, 14313 14326, doi:10.1029/2001JD900048, 2001.

Randel, W. J., Wu, F., Oltmans, S. J., Rosenlof, K., and Nedoluha, G. E.: Interannual Changes of Stratospheric Water Vapor and Correlations with Tropical Tropopause Temperatures., J. Atmos. Sci., 61, 2133-2148, 2004.

Randel, W. J., Wu, F., Vömel, H., Nedoluha, G. E., and Forster, P.: Decreases in stratospheric water vapor after 2001: Links to changes in the tropical tropopause and the BrewerDobson circulation, J. Geophys. Res., 111, 12 312, doi:10.1029/ 2005JD006744, 2006.

Reinsel, G. C., Weatherhead, E., Tiao, G. C., Miller, A. J., Nagatani, R. M., Wuebbles, D. J., and Flynn, L. E.: On detection of turnaround and recovery in trend for ozone, J. Geophys. Res., 107, n.a., doi:10.1029/2001JD000500, 2002.

Rohs, S., Schiller, C., Riese, M., Engel, A., Schmidt, U., Wetter, T., Levin, I., Nakazawa, T., and Aoki, S.: Long-term changes of methane and hydrogen in the stratosphere in the period 1978-2003 and their impact on the abundance of stratospheric water vapor, J. Geophys. Res., 111, 14315, doi:10.1029/ 2005JD006877, 2006.

Rosenlof, K. H., Chiou, E.-W., Chu, W. P., Johnson, D. G., Kelly, K. K., Michelsen, H. A., Nedoluha, G. E., Remsberg, E. E., Toon, G. C., and McCormick, M. P.: Stratospheric water vapor increases over the past half-century, Geophys. Res. Lett., 28, 1195-1198, doi:10.1029/2000GL012502, 2001.

Russell, III, J. M., Gordley, L. L., Park, J. H., Drayson, S. R., Hesketh, W. D., Cicerone, R. J., Tuck, A. F., Frederick, J. E., Harries, J. E., and Crutzen, P. J.: The Halogen Occultation Experiment, J. Geophys. Res., 98, 10777-10 798, 1993.

Scaife, A. A., Butchart, N., Jackson, D. R., and Swinbank, R.: Can changes in ENSO activity help to explain increasing stratospheric water vapor?, Geophys. Res. Lett., 30(17), 1880, doi:10.1029/2003GL017591, 2003.

Seidel, D. J., Ross, R. J., Angell, J. K., and Reid, G. C.: Climatological characteristics of the tropical tropopause as revealed by radiosondes, J. Geophys. Res., 106, 7857-7878, doi:10.1029/ 2000JD900837, 2001.

Sherwood, S.: A Microphysical Connection Among Biomass Burning, Cumulus Clouds, and Stratospheric Moisture, Science, 295, 1272-1275, doi:10.1126/science.1065080, 2002.

Shindell, D. T.: Climate and ozone response to increased stratospheric water vapor, Geophys. Res. Lett., 28, 1551-1554, doi: 10.1029/1999GL011197, 2001.

Sobel, A. H., Plumb, R. A., and Waugh, D. W.: Methods of Calculating Transport across the Polar Vortex Edge., J. Atmos. Sci., 54, 2241-2260, 1997. 
Stenke, A. and Grewe, V.: Simulation of stratospheric water vapor trends: impact on stratospheric ozone chemistry, Atmos. Chem. Phys., 5, 1257-1272, 2005, http://www.atmos-chem-phys.net/5/1257/2005/.

Vömel, H., Oltmans, S. J., Hofmann, D. J., Deshler, T., and Rosen, J. M.: The evolution of the dehydration in the Antarctic stratospheric vortex, J. Geophys. Res., 100, 13919-13926, doi:10.1029/95JD01000, 1995.

Vömel, H., David, D. E., and Smith, K.: Accuracy of tropospheric and stratospheric water vapor measurements by the cryogenic frost point hygrometer: Instrumental details and observations, J. Geophys. Res., 112, 8305, doi:10.1029/2006JD007224, 2007a.
Vömel, H., Yushkov, V., Khaykin, S., Korshunov, L., Kyrö, E., and Kivi, R.: Intercomparison of stratospheric water vapor sensors: FLASH-b and NOAA/CMDL frost point hygrometer, J. Atmos. Ocean. Tech., 27, 941-952, doi:10.1175/JTECH2007.1, $2007 \mathrm{~b}$.

Waugh, D. and Hall, T.: Age of stratospheric air: theory, observations, and models, Rev. Geophys., 40, 1-1, doi:10.1029/ 2000RG000101, 2002.

Weatherhead, E. C. and Andersen, S. B.: The search for signs of recovery of the ozone layer, Nature, 441, 39-45, 2006.

Zhou, X.-L., Geller, M. A., and Zhang, M.: Cooling trend of the tropical cold point tropopause temperatures and its implications, J. Geophys. Res., 106, 1511-1522, doi:10.1029/2000JD900472, 2001. 